\title{
Working Memory Tasks Reflections on Electrical Activity of the Brain
}

\author{
Magdy Aly El-Barbary \\ Physiology Department, Faculty of Medicine, Suez Canal University
}

\begin{abstract}
Introduction \& rationale: Recent theoretical and experimental work has focused on the changes of electro encephalographic waves in working memory and there has been particular interest in oscillations in the theta and alpha frequency bands. It is apparent that there are a lot of discrepancies among findings of different studies concerning EEG during memory tasks. Aim of the work: was to assess changes in the electric activity of the brain during working memory tasks. Subjects \& Methods: A cross-sectional descriptive study was done in the EEG unit in Suez Canal University hospital to reveal the changes that occur in the electric activity of the brain during Sternberg memory task performance. 43 subjects volunteered to our study. They all underwent EEG recording during performance of a visual Sternberg memory task. This EEG record was compared to another baseline EEG record done before task performance to monitor the changes that occurred in the electric activity of the brain. Results: Analysis of the EEG waves in parietal temporal and occipital brain areas revealed that: There is significant difference between peak power frequency (PPF) before and during task performance. As PPF in the theta band was significantly more frequent during the task performance than before task performance $(P<0.05)$. While PPF at central electrodes, in most of the subjects, have no significant difference before and during task performance in the theta band. While theta waves are significantly more frequent during the task performance than before task performance at $C Z(P<0.05)$. There was a significant change in the Relative Power of beta1, beta 2 frequency band before and during task performance with $P$ value $<0.05$. There was non-significant change in the Relative Power of other frequency bands before and during task performance $(P>0.05)$. in addition the degree of task performance was strongly correlated with power of beta 1 and delta bands before task performance. Conclusions: We concluded that working memory task is reflected on the electric activity of the brain in the form of peak power frequency in the range of theta oscillations in parietal, occipital, temporal areas of the brain. There was a significant increase in the relative power of beta 1, beta 2 frequency bands during task performance. However, degree of task performance was strongly related to the relative powers of beta 1 and delta frequency bands before task performance.
\end{abstract}

Key words: working memory tasks, EEG, Peak power frequency

\section{INTRODUCTION}

Cognitive neuroscience now leaves no or little doubt that electroencephalogram (EEG) is closely connecting to brain dynamics, information processing, and cognitive $\operatorname{activity}^{(\mathbf{1})}$.

Jensen and colleagues examined EEG recorded during the Sternberg 
working memory task and they found that the presence of alpha band activity during the retention period of the Sternberg task appears to be a robust finding. Examination of the power spectrum showed a clear peak in the alpha band at 9-12 Hz. A peak in the theta band was not detected except in one subject ${ }^{(2)}$.

It is apparent that a big discrepancy was reported among findings of different studies concerning EEG during memory tasks. Accurate recording and analysis of brain oscillations during memory tasks might help in defining the brain regions responsible for memory processes. In order to record brain electric activity (and oscillations) from the scalp by means of the EEG, large cortical regions of at least $6 \mathrm{~cm}$ have to be involved in the generation of the same EEG pattern to be synchronized $^{(3)}$.

\section{Aim of the work}

Is to assess changes in the electric activity of the brain during working memory tasks

\section{SUBJECTS \& METHODS}

\section{Study site:}

The study was carried out in Suez Canal University Hospital in the electroencephalography unite.

Type of the study: is Cross sectional descriptive study.

Subjects:

Target population includes 43 Normal healthy volunteers of same age, and of both sex.

Methods:

All subjects underwent EEG recording during performance of a visual Sternberg memory task. This EEG record was compared to another baseline EEG record done before task performance to monitor the changes that occurred in the electric activity of the brain.

a. EEG Apparatus

Neuroscan medical system EEG device was used.

b. Electrodes

- We placed pairs of electrodes, using a standardized system of sites that uses bony landmarks as reference points for placement. Electrodes were positioned at points which are 10 or $20 \%$ along interlandmark lines, and the system (the international 10-20) provides intra- and interpatient repeatability of EEG recordings $^{(4)}$.

- Unipolar montages were used in this study where we placed one electrode over cortex and one is the average between the 2 electrodes at the 2 ear lobes.

- Filters used were in the pass band of $(0.5-70 \mathrm{~Hz})$ as it was the range that was used in clinical practice of $\mathrm{EEG}^{(4)}$.

- Montages where frontal electrodes are involved are not interpreted so as to avoid eye artifacts and blink movements as they will be abundant during recording as the task depends on visual stimulii.

c-Sternberg memory search paradigm - Apparatus and stimuli

An IBM computer controlled presentation of the stimuli. Subjects sat comfortably in front of a cathode ray screen and on each trial responded by raising their index finger.

- Procedure

- Subjects sat in an isolated room comfortably, with no noise and temperature controlled. 
- After the subject became ready, the memory set of two, three, or four digits or letters was presented at the rate of 1.2 seconds per stimulus (digit or letter) where there was 1 second for the presentation of each stimulus followed by a blank screen for 0.2 seconds.

- After a 2 second pause and a 0.5 second warning signal a test item was displayed and remained on the screen until the subject responded whether it is from the memory set or not.

- There was 30 trials, where the test item was of the memory set in half of the trials and in the other half it was not.

- Concerning the 30 trials, 10 of them had a memory set of two stimuli , the second 10 trials had a memory set of three stimuli, the last 10 trials had a memory set of four stimuli ${ }^{(\mathbf{5})}$.

d. Method of analysis of the obtained EEG recordings

Spectral displays with automated techniques were used as follows:

The spectrum was divided into the classic neurological frequency bands (alpha 1, alpha 2, beta 1 , beta 2 , delta, theta) \& computed the total power for each band (voltage squared). So the peak power frequency (PPF) in the spectrum for each montage was obtained where PPF is defined as the frequency in the spectrum that displays the highest power in a particular epoch. Relative power then follows where it was defined as the ratio of power in a band divided by the total power in all bands combined $^{(4)}$.

PPF was defined in each montage both before and during the task. In addition, the relative power for each frequency band was obtained both before and during the task.

Frequency bands are defined as follows: Delta waves ( 0.5-4 Hz), Theta waves ( 4-8 Hz), Alpha 1 waves ( 8-11 Hz), Alpha 2 waves ( 11-14 $\mathrm{Hz})$, Beta 1 waves $(14-25 \mathrm{~Hz})$, Beta 2 waves $(25-35 \mathrm{~Hz})$.

Activity of the relative power was also observed where the increase in relative power of a certain frequency band was termed synchronization while the decrease in relative power was termed desynchronization.

\section{RESULTS}

Study population was 43 subjects: The range of age was from 14 to 18 years old, $25.6 \%$ of them were females \& $74.4 \%$ of them were males. All the subjects performed Sternberg memory task and $51.2 \%$ of them obtained degree from $95 \%$ to $100 \%$.

By doing Spectral analysis of EEG recordings, Peak Power Frequency (PPF) at recording electrodes obtained before and during task performance and it was as follows:

\section{Temporal Electrodes}

Table (1) shows PPF at temporal electrodes before and during task performance. There is significant difference between PPF at T3, T4, T5, T6 before and during task performance as PPF was significantly more frequent in the theta band during the task performance than before task performance. $(\mathrm{P}<0.05)$

\section{Parietal Electrodes}

Table (1) shows PPF at parietal electrodes before and during task performance. There is significant difference between PPF at P3, P4, PZ 
before and during task performance as PPF in the theta band was significantly more frequent during the task performance than before task performance. $(\mathrm{P}<0.05)$

\section{Occipital Electrodes}

Table (1) shows PPF at occipital electrodes before and during task performance. There is significant difference between PPF at $\mathrm{O} 1, \mathrm{O} 2$ before and during task performance as PPF in the theta band was significantly more frequent during the task performance than before task performance. $(\mathrm{P}<0.05)$

\section{Central Electrodes}

Table (1) shows PPF at central electrodes before and during memory task performance. Most of the subjects (at central electrodes) have no significant difference in PPF before and during task performance in the theta band. There is no significant difference between PPF at either C3 or $\mathrm{C} 4$ before and during task performance while theta waves are significantly more frequent during the task performance than before task performance at $\mathrm{CZ}(\mathrm{P}<0.05)$.

Table (1): (Peak Power Frequency-PPF) at electrodes before and during task performance

\begin{tabular}{|c|c|c|c|c|c|c|c|c|c|c|}
\hline & \multicolumn{2}{|c|}{ Alpha 1} & \multicolumn{2}{|c|}{ Alpha 2} & \multicolumn{2}{|c|}{ Theta } & \multicolumn{2}{|c|}{ Total } & \multirow{2}{*}{$\mathrm{X}^{2}$} & \multirow{2}{*}{$P$ value } \\
\hline & No. & $\%$ & No. & $\%$ & No. & $\%$ & No. & $\%$ & & \\
\hline T3 before & 22 & 51.2 & 2 & 4.7 & 19 & 44.2 & 43 & 100 & \multirow{2}{*}{23.437} & \multirow{2}{*}{$0.000 *$} \\
\hline T3 during & 10 & 23.3 & 4 & 9.3 & 29 & 67.4 & 43 & 100 & & \\
\hline T4 before & 21 & 48.8 & 2 & 4.7 & 20 & 46.5 & 43 & 100 & \multirow{2}{*}{24.109} & \multirow{2}{*}{$0.000 *$} \\
\hline T4 during & 10 & 23.3 & 4 & 9.3 & 29 & 67.4 & 43 & 100 & & \\
\hline T5 before & 30 & 69.8 & 2 & 4.7 & 11 & 25.6 & 43 & 100 & \multirow{2}{*}{17.750} & \multirow{2}{*}{$0.001 *$} \\
\hline T5 during & 15 & 34.9 & 6 & 14 & 22 & 51.2 & 43 & 100 & & \\
\hline T6 before & 30 & 69.8 & 2 & 4.7 & 11 & 25.6 & 43 & 100 & \multirow{2}{*}{17.750} & \multirow{2}{*}{ 0.001* } \\
\hline T6 during & 15 & 34.9 & 6 & 14 & 22 & 51.2 & 43 & 100 & & \\
\hline P3 before & 24 & 55.8 & 4 & 9.3 & 15 & 34.9 & 43 & 100 & \multirow{2}{*}{19.014} & \multirow{2}{*}{$0.001 *$} \\
\hline P3 during & 14 & 32.6 & 4 & 9.3 & 25 & 58.1 & 43 & 100 & & \\
\hline P4 before & 24 & 55.8 & 4 & 9.3 & 15 & 34.9 & 43 & 100 & \multirow{2}{*}{19.014} & \multirow{2}{*}{$0.001 *$} \\
\hline P4 during & 14 & 32.6 & 4 & 9.3 & 25 & 58.1 & 43 & 100 & & \\
\hline Pz before & 27 & 62.8 & 1 & 2.3 & 15 & 34.9 & 43 & 100 & \multirow[b]{2}{*}{20.946} & \multirow{2}{*}{ 0.000* } \\
\hline Pz during & 14 & 32.6 & 4 & 9.3 & 25 & 58.1 & 43 & 100 & & \\
\hline O1 before & 36 & 83.7 & 4 & 9.3 & 3 & 7 & 43 & 100 & \multirow{2}{*}{19.415} & \multirow{2}{*}{$0.001 *$} \\
\hline O1 during & 22 & 51.2 & 6 & 14 & 15 & 34.9 & 43 & 100 & & \\
\hline O2 before & 36 & 83.7 & 4 & 9.3 & 3 & 7 & 43 & 100 & \multirow{2}{*}{19.415} & \multirow{2}{*}{ 0.001* } \\
\hline O2 during & 22 & 51.2 & 6 & 14 & 15 & 34.9 & 43 & 100 & & \\
\hline C3 before & 8 & 18.6 & 2 & 4.7 & 33 & 76.6 & 43 & 100 & \multirow{2}{*}{1.862} & \multirow{2}{*}{0.394} \\
\hline C3 during & 5 & 11.6 & 0 & 0 & 38 & 88.4 & 43 & 100 & & \\
\hline C4 before & 7 & 16.3 & 2 & 4.7 & 34 & 79.1 & 43 & 100 & \multirow{2}{*}{3.406} & \multirow{2}{*}{0.333} \\
\hline C4 during & 5 & 11.6 & 0 & 0 & 38 & 88.4 & 43 & 100 & & \\
\hline Cz before & 6 & 14 & 1 & 2.3 & 36 & 83.7 & 43 & 100 & \multirow{2}{*}{19.014} & \multirow{2}{*}{ 0.001* } \\
\hline $\mathrm{Cz}$ during & 3 & 7 & 0 & 0 & 40 & 93 & 43 & 100 & & \\
\hline
\end{tabular}

Before $=$ before task performance During = during task performance

$X^{2}=$ chi square test

significant $=P<0.05$

highly significant $=P<0.01$ 
Relative Power (\% of total brain activity) of the different frequency bands was obtained before and during task performance.

On comparing means of Relative Power of different frequency bands before and during task performance, the results revealed the following:

There was a significant increase in the Relative Power of beta1, beta 2 frequency band before and during task performance with $\mathrm{P}$ value $<0.05$. The other frequency bands (Delta, Theta, Alpha 1, Alpha 2) didn't show any significant change. $(\mathrm{P}>0.05)$.

Correlation analysis of Sternberg task performance and the Relative Power of different frequency bands

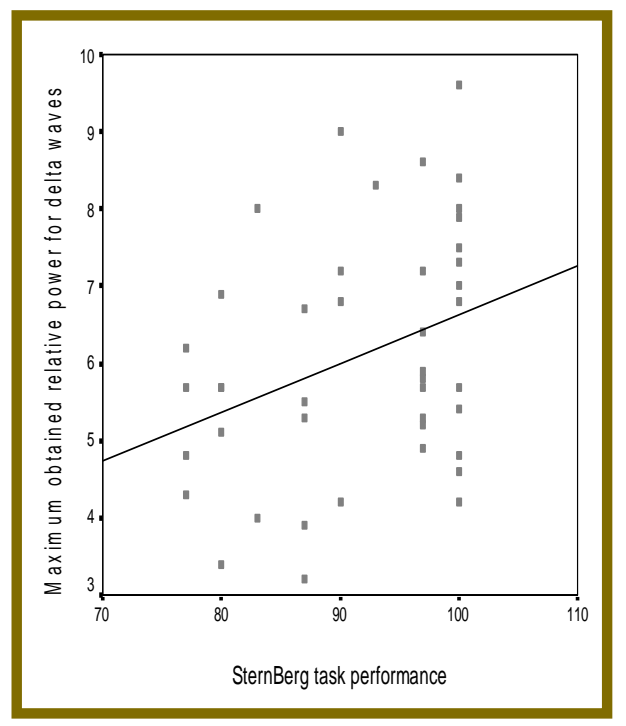

Fig (1) both before and during task performance revealed the follows:

There was a significant positive correlation $(\mathrm{P}<0.05)$ between degree of Sternberg task performance and the Relative Power of delta waves before task performance. In addition, a significant negative correlation between degree of task performance and the relative power of beta 2 waves before task performance recorded. However there is non-significant correlation $(\mathrm{P}>0.05)$ between degree of task performance and the relative power of other types of waves either before or during the task performance. (fig.: $1 \& 2$ ).

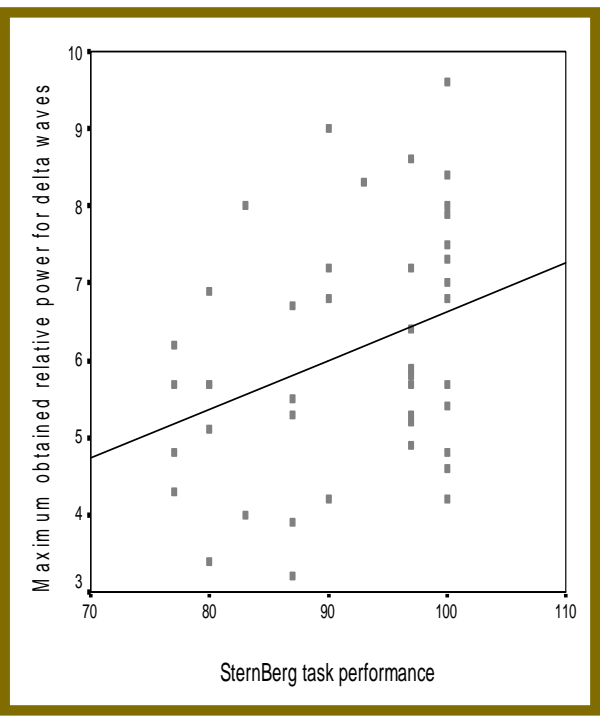

Fig (2) 


\section{DISCUSSION}

This study aimed to reveal changes that occur in brain activity during working memory tasks. Study population was 43 subjects: $25.6 \%$ of them were females \& $74.4 \%$ of them were males. All the subjects performed Sternberg memory task while undergoing electroencephalography (EEG) recording. Any change observed during performance of the task could be attributed to memory activity as the baseline brain activity recorded before achievement of the task was done while the subjects were looking at the same computer screen they watch during the task and increasingly the screen showed one of the stimuli that were used during the task. This was done to ensure that the results obtained are due to working memory task and not because of the visual sense involvement.

By doing Spectral analysis of EEG recordings, peak power frequency (PPF) at recording electrodes was obtained before and during task performance and it was found that there is significant relation between PPF before \& during task performance at P3, P4, PZ, T3, T4, T5, T6, O1, O2. As there is a significant increase in number of subjects with theta activity at the parietal, temporal \& occipital areas, so these areas may be involved in working memory.

This is consistent with study that revealed electric activity in the lateral and posterior areas on performing memory tasks. They used the same memory task used in our study, which is Sternberg memory task ${ }^{(2)}$.

Studies have investigated the anatomical bases of working memory by looking for brain regions where the hemodynamic response correlated with memory load. These regions were shown to be medial temporal regions and this finding was consistent with our study as hemodynamic response is an indicator of involvement of these areas in working memory ${ }^{(6)}$.

Our results are also consistent with what Raghavachari found, as this study revealed that a substantial fraction of sites in the occipital/ parietal and temporal cortices were gated by the working memory task and this aspect of working memory function was virtually absent in frontal cortex ${ }^{(7)}$.

On analyzing the relative power of different frequency bands, the change that occurred in the relative power of beta band was significant, while there is non-significant change in all the other bands. All other studies showed significant change in either theta, alpha or gamma bands. Beta rhythm $(>20 \mathrm{~Hz})$ activity reflects the activity of the motor cortices ${ }^{(8)}$. Beta rhythm responses have been observed also during observation of other's movements and during motor imagery $^{(\mathbf{9})}$. So, the significant change in the beta band might be because of observation of the running stimuli of the task or it might because of its involvement in working memory.

In our study, the gamma band, which is around $40 \mathrm{~Hz}$, was not studied, as the filter maximum limit was $35 \mathrm{~Hz}$. In studies using various 
tasks, separate foci of simultaneously occurring oscillations around $40 \mathrm{~Hz}$ in cortical regions, have been reported. High-frequency brain oscillations may be related to the rapid binding of sensory information in different brain $\operatorname{areas}^{(9)}$.

\section{Conclusions}

1. Working memory tasks could be reflected on the electric activity of the brain in the form of prominent theta oscillations in parietal, occipital and temporal areas of the brain.

2. Majority of the population had desynchronization in the low frequency bands (delta, theta, alpha 1) during task performance, while most of them had synchronization in the high frequency bands (alpha 2 , beta 1 , beta 2 ).

3 . The relative power of beta 1 and beta 2 frequency bands during task performance showed significant changes.

4. Degree of task performance was strongly related to the relative powers of beta 1 and delta frequency bands before task performance

\section{REFERENCES}

1. Nunez, P.L., (2000): Toward a quantitative description of largescale neocortical dynamic function and EEG. Behav. Brain Sci. 23, 371-437.

2. Jensen O, Tesche CD, (2002): Frontal theta activity in humans increases with memory load in a working memory task. Eur J
Neurosci 15: 1395-1399.

3. Fingelkurts, Al.A., Fingelkurts, An.A., Kaplan, A. ,Krause C., (2003): Structural (operational) synchrony of EEG alpha activity during an auditory memory task. Neuroimage 20 529-542.

4. Sebel P.S., Fitch W., (1994): Monitoring the central nervous system, 241-243, Blackwell science

(http://www.unlv.edu/faculty/pjo nes/nltest_1.htm\#STRN)

5. Stern CE, Sherman SJ, Kirchhoff BA, Hasselmo ME, (2001): Medial temporal and prefrontal contributions to working memory tasks with novel and familiar stimuli. Hippocampus 11:337-346.

6. Raghavachari S. , J. E. Lisman, M. Tully, J. R. Madsen, E. B. Bromfield and M. J. Kahana, (2005) : J Neurophysiol 95: 16301638, Theta Oscillations in Human Cortex During a Working-Memory Task: Evidence for Local Generators

7. Pfurtscheller, G., K. Zalaudek, and C. Neuper, (1998) : Eventrelated beta synchronization after wrist, finger and thumb movement. Electroencephalogr Clin Neurophysiol,. 109: p. 15460.

8. Basar, E., C. Basar-Eroglu, S. Karakas, and M. Schurmann, (2000) :"Brain oscillations in perception and memory." International Journal of Psychophysiology 35 (2-3) : 95124. 


\title{
التذبذبات المخية أثناء مهمات الذاكرة العاملة
}

\author{
مجدي على البربري \\ قسم الفسيولوجي ، جامعةٌ قناة السويس، جامعة قناة السويس
}

من المقترح أن التذبذبات الكهربائية للمخ تلعب دور هام عندما نحاول فهم الأساس العصبي للعمليات

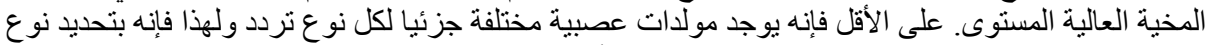

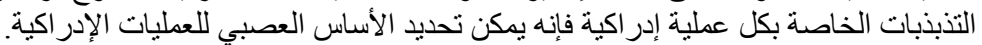

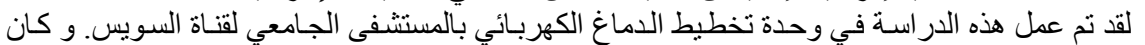

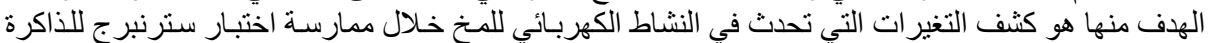

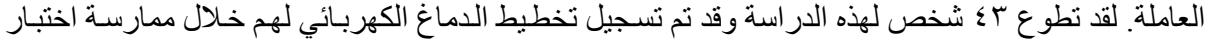
سترنبرج المرئي للذاكرة العاملة. وقد تم مقارنـة هذا التخطيط بتخطيط آخر تم تسجيله بدون ممارسة أي اختبار ات لكي يسهل مر اقبـة التغيرات التي تحدث في النثاط الكهرب بائي للكخ. وقد ثبت من خلال هذه الدر اسة أن اختبار الذاكرة العاملة ينعكس على النشاط الكهربائي للمخ فى صورة

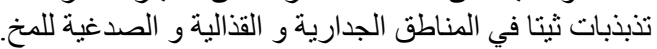

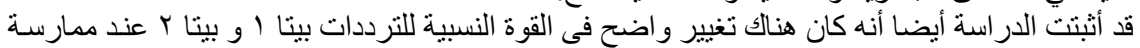

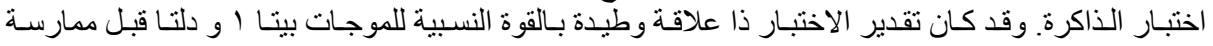

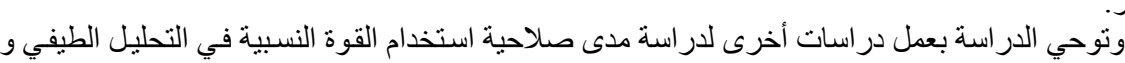

كما توحي الدراسة أيضا بعمل دورات تدريبية في التحليل الطيفي لتخطيط الدماغ حيث أن الخلفية العلمية

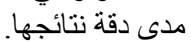

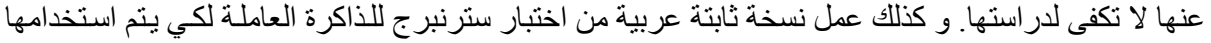
في البحث العلمي في المناطق الناطقة باللغة العربية. 